\title{
The influence of the glycaemic index of breakfast and lunch on substrate utilisation during the postprandial periods and subsequent exercise
}

\author{
Emma Stevenson, Clyde Williams* and Maria Nute \\ Sport and Exercise Nutrition Research Group, School of Sport and Exercise Sciences, Loughborough University, Loughborough, \\ Leicestershire, LE11 3TU, UK
}

(Received 20 August 2004 - Revised 11 January 2005 - Accepted 17 January 2005)

\begin{abstract}
The present study investigated the effects of mixed high-carbohydrate (CHO) meals (breakfast and lunch) with different glycaemic indices (GI) on substrate metabolism during rest throughout the postprandial periods and during subsequent exercise. Nine recreationally active males completed two trials, high glycaemic index (HGI) and low glycaemic index (LGI), separated by $7 \mathrm{~d}$ in a randomised crossover design. In each trial, participants consumed breakfast and lunch, both of which were followed by a $3 \mathrm{~h}$ resting postprandial period. Following this, participants completed a 60 min run at $70 \%$ of $\dot{\mathrm{VO}} 2 \mathrm{max}$. The plasma glucose and serum insulin concentrations following both meals were significantly higher in the HGI trial than in the LGI trial $(P<0 \cdot 05)$. Serum insulin concentrations remained higher throughout the postprandial period following lunch in the HGI trial compared with the LGI trial $(P<0 \cdot 05)$. The total amount of fat oxidised was higher during the $3 \mathrm{~h}$ rest following lunch in the LGI trial than in the HGI trial $(P<0 \cdot 01)$ and subsequently CHO oxidation was lower $(P<0.005)$. No significant differences in substrate utilisation were observed throughout the subsequent run. At 45 and 60 min, plasma glucose concentrations were higher in the LGI trial $v$. the HGI trial $(P<0 \cdot 05)$. The results of the present study provide further support that the GI concept can be successfully applied to mixed meals. The results also suggest that meals composed of LGI CHO may be more beneficial for maintaining a favourable metabolic milieu during the postprandial periods. Furthermore, during subsequent exercise, plasma glucose concentrations were better maintained following the LGI CHO meals.
\end{abstract}

Glucose: Insulin: Mixed meals: Fat oxidation: Exercise

The ingestion of carbohydrate (CHO) before exercise is beneficial as it increases both muscle and liver glycogen stores (Nilsson \& Hultman, 1973). Nevertheless, a high CHO intake also alters the metabolic responses and substrate utilisation during exercise (Coyle et al. 1997). A number of studies have observed a depression in the rate of fat oxidation following $\mathrm{CHO}$ ingestion due to hyperinsulinaemia in the postprandial period (Horowitz et al. 1997; Wee et al. 1999; Wu et al. 2003). However, altering the type of $\mathrm{CHO}$ consumed has been shown to have an effect on the magnitude of hyperinsulinaemia and therefore depression of fat oxidation (Wee et al. 1999; Wu et al. 2003).

It has repeatedly been shown that consumption of low glycaemic index (LGI) CHO results in lower insulinaemic and glycaemic responses during rest in the postprandial period than does consumption of high glycaemic index (HGI) CHO. Several studies have therefore manipulated the glycaemic index (GI) of pre-exercise feedings and have reported a higher rate of fat oxidation and a better maintenance of plasma glucose concentrations during subsequent exercise after ingesting a single LGI CHO food compared with a single HGI CHO food (Thomas et al. 1991, 1994; Febbraio \& Stewart, 1996; Sparks et al. 1998; Wee et al. 1999).

The metabolic responses to single foods with a HGI or LGI are clear; however, it is not common practice to eat single foods at meal times in daily life. Research into the metabolic responses to mixed meals containing foods with different GI values is fairly limited despite its obvious applicability to real life. It has previously been reported that the GI concept lacks clinical utility because the differences in GI between foods are lost once these foods are consumed in a mixed meal (Coulston et al. 1987). A study carried out by DeMarco et al. (1999) compared the postprandial glycaemic, insulinaemic and physiological responses to pre-exercise mixed meals composed of either HGI or LGI $\mathrm{CHO}$. No differences in the glycaemic responses were reported between the meals; however, the total energy, fat and protein content of the two test meals were not matched. The addition of fat to a $\mathrm{CHO}$ meal enhances insulin secretion but also decreases the plasma glucose response (Collier et al. 1984). Similarly, adding protein to a $\mathrm{CHO}$ meal increases the insulin secretion without augmenting glucose concentrations (Pi-Sunyer, 2002). Therefore, to compare mixed meals accurately, it is important that the non$\mathrm{CHO}$ sources in the meals are matched.

A recent study from our laboratory investigated the effect of consuming mixed breakfasts containing either HGI or LGI $\mathrm{CHO}$ on substrate utilisation during exercise performed $3 \mathrm{~h}$ later. Both breakfasts were matched in terms of energy and nutrients. In agreement with studies carried out on single foods, the HGI meal resulted in a significantly greater glycaemic and 
insulinaemic response during the postprandial period. It was also reported that the calculated amount of fat oxidation was significantly higher during exercise commencing $3 \mathrm{~h}$ after consuming the LGI mixed meal compared with when the HGI mixed meal was consumed (Wu et al. 2003).

To date, no studies have been carried out to investigate the effects of two HGI or LGI mixed CHO meals on resting postprandial metabolism and substrate utilisation during subsequent exercise. Many individuals exercise in the afternoon after work and will therefore consume breakfast and lunch before the exercise session. Based on previous research already described, one would expect consistently higher glycaemic and insulinaemic responses to HGI mixed meals than to LGI mixed meals. It is also hypothesised that the rate of fat oxidation would be higher during exercise following two LGI meals compared with two HGI meals. Therefore, the aim of the present study was to investigate the effects of changing the GI of the $\mathrm{CHO}$ within two mixed meals (breakfast and lunch) on the postprandial metabolic responses and substrate utilisation during rest and during a subsequent 60 min run at $70 \%$ of $\dot{\mathrm{VO}}_{2 \max }$.

\section{Methods}

\section{Subjects}

Nine male recreational athletes participated in the study. Their mean age, height, weight and $\dot{\mathrm{V}} \mathrm{O}_{2 \max }$ were 23.7 (SD 2.1) years, 177.0 (SD 1.0) cm, 74.3 (SD 7.0) $\mathrm{kg}$ and 64.6 (SD 5.6) $\mathrm{ml} / \mathrm{kg}$ per min, respectively. None of the subjects recruited was consuming any food supplements, medication or recreational drugs. Loughborough University Ethical Advisory Committee approved the protocol and all subjects gave their written informed consent.

\section{Preliminary testing}

Following familiarisation with treadmill running and experimental procedures, subjects undertook two preliminary tests to determine first the relationship between running speed and oxygen uptake using a $16 \mathrm{~min}$ incremental test and, second, their $\dot{\mathrm{V}} \mathrm{O}_{2 \max }$ using an uphill incremental treadmill test to exhaustion. All preliminary tests were conducted according to procedures described previously (Williams et al. 1990). Based on the results of the two preliminary tests, the running speed equivalent to $70 \%$ of each subject's $\dot{\mathrm{VO}}_{2 \max }$ was determined.

\section{Experimental design}

Each subject participated in two experimental trials separated by a week. On each occasion, subjects were provided with two meals (breakfast and lunch), which were both followed by $3 \mathrm{~h}$ rest. Following the $3 \mathrm{~h}$ postprandial period after lunch, subjects ran for 60 min on a motorised treadmill at $70 \% \dot{\mathrm{VO}}_{2 \max }$. The test meals were composed mainly of either HGI or LGI $\mathrm{CHO}$ and the order of the trials was randomised.

All trials were performed at the same time of day and under similar experimental and environmental conditions. The same treadmill was also used throughout the experiment (Technogym $^{\text {тм }}$ Run Race Treadmill 47035; Technogym, Gambettoio, Italy). For $24 \mathrm{~h}$ before the first trial, the subjects recorded their diet and exercise routine so that it could be repeated before the second trial to minimise differences in pre-testing intramuscular substrate concentrations between experimental trials. Subjects were advised to maintain their normal training schedule during the study but to abstain from any vigorous exercise in the $24 \mathrm{~h}$ period before the two experimental trials. During this period they were also instructed to avoid alcohol, caffeine and smoking.

\section{Protocol}

On the day of the experiment each subject arrived in the laboratory at 08.00 hours following $12 \mathrm{~h}$ overnight fast. On arrival, subjects completed the necessary health and consent forms and were then asked to void before nude mass was obtained (Avery, London, UK). After weighing, a cannula (Venflon 18G; Becton Dickinson Ltd, Helsingborg, Sweden) was inserted into an antecubital vein while the subject was lying on an examination couch. Basal blood and gas samples were obtained once the subject had sat for $10 \mathrm{~min}$. The first test meal was then served and the subjects were asked to consume it within $30 \mathrm{~min}$. After finishing this meal, the first $3 \mathrm{~h}$ postprandial period began. During this time, subjects were asked to remain seated, avoiding any physical activity. Immediately after the $3 \mathrm{~h}$ postprandial period, the second meal was served. Again, subjects were asked to consume the meal within $30 \mathrm{~min}$ and then the second $3 \mathrm{~h}$ postprandial period began. Following this, subjects were weighed and then changed into running attire. A short-range telemeter (Technogym) heart-rate monitor was then attached to the subject to monitor heart rate. Heart rate was monitored closely throughout the run and values recorded during each 1 min collection of expired air. Before commencing the $60 \mathrm{~min}$ run at $70 \% \dot{\mathrm{VO}}_{2 \max }$, subjects completed a 5 min warm-up at $60 \% \dot{\mathrm{VO}}_{2 \max }$.

Ambient temperature and relative humidity were recorded at $30 \mathrm{~min}$ intervals during the postprandial period and at $15 \mathrm{~min}$ intervals throughout the run using a hygrometer (Zeal, London, UK). Temperature was maintained between 16 and $22^{\circ} \mathrm{C}$ and humidity was $50-60 \%$ in all trials.

\section{Test meals}

In each trial, two mixed meals consisting of HGI or LGI CHO were provided for each subject and each meal provided approximately $2 \mathrm{~g} \mathrm{CHO} / \mathrm{kg}$ body mass (Table 1 ). The nutritional content of each meal was calculated from information provided by the manufacturer. Both diets consisted of $72 \% \mathrm{CHO}, 11 \%$ fat and $17 \%$ protein. The GI of the total diets was calculated from the weighted means of the GI values for the component foods (Wolever \& Jenkins, 1986). The GI values for the individual foods were taken from the international table of glycaemic index and glycaemic load values: 2002 (Foster-Powell et al. 2002). The calculated GI for the high and low breakfast was 76 and 44, respectively. The GI value for the HGI lunch was 73 and the LGI lunch was 34.

\section{Blood sample collection and analysis}

All blood samples taken during the postprandial period were obtained from the subject whilst seated. In addition to the basal blood sample, further samples were taken at 15, 30, 60, 90, 120 and $180 \mathrm{~min}$ after each meal and at $15 \mathrm{~min}$ intervals during exercise.

At each sampling point, $7 \mathrm{ml}$ blood was collected and $4 \mathrm{ml}$ whole blood was immediately dispensed into an EDTA tube. $\mathrm{Hb}$ concentration was determined using the cyanmethaemoglobin 
Table 1. Characteristics of the test meals (for a $70 \mathrm{~kg}$ person)

\begin{tabular}{|c|c|c|}
\hline Meal & Description & Macronutrient content \\
\hline HGI breakfast & $\begin{array}{l}62 \mathrm{~g} \text { Corn Flakes }{ }^{*}+257 \mathrm{ml} \text { skimmed milk, } 80 \mathrm{~g} \text { white bread }+ \\
10 \mathrm{~g} \mathrm{Flora}^{*}+20 \mathrm{~g} \mathrm{jam}, 155 \mathrm{ml}^{2} \text { Lucozade Original }{ }^{*}\end{array}$ & $3066 \mathrm{kj}(730 \mathrm{kcal}), 139 \mathrm{~g} \mathrm{CHO}, 9.9 \mathrm{~g}$ fat, $20 \mathrm{~g}$ protein \\
\hline LGI breakfast & $\begin{array}{l}86 \mathrm{~g} \text { muesli }+257 \mathrm{ml} \text { skimmed milk, } 67 \mathrm{~g} \text { apple, } 103 \mathrm{~g} \text { tinned } \\
\text { peaches, } 128 \mathrm{~g} \text { yoghurt, } 257 \mathrm{ml} \text { apple juice }\end{array}$ & $3074 \mathrm{kj}(732 \mathrm{kcal}), 139 \mathrm{~g} \mathrm{CHO}, 9 \mathrm{~g}$ fat, $23 \mathrm{~g}$ protein \\
\hline HGI lunch & $\begin{array}{l}158 \mathrm{~g} \text { white bread, } 154 \mathrm{~g} \text { turkey breast, } 50 \mathrm{~g} \text { cheese, } \\
40 \mathrm{~g} \text { lettuce, } 180 \mathrm{~g} \text { banana, } 200 \mathrm{ml}^{\text {Lucozade Original }}{ }^{*}\end{array}$ & $4519 \mathrm{kj}(1076 \mathrm{kcal}), 148 \mathrm{~g} \mathrm{CHO}, 24 \mathrm{~g}$ fat, $63 \mathrm{~g}$ protein \\
\hline LGI lunch & $\begin{array}{l}154 \mathrm{~g} \text { whole-wheat pasta, } 150 \mathrm{~g} \text { turkey breast, } 50 \mathrm{~g} \text { cheese, } \\
40 \mathrm{~g} \text { lettuce, } 185 \mathrm{~g} \text { pasta sauce, } 150 \mathrm{~g} \text { pear, } 150 \mathrm{ml} \text { apple juice }\end{array}$ & $4515 \mathrm{kj}(1075 \mathrm{kcal}), 149 \mathrm{~g} \mathrm{CHO}, 25 \mathrm{~g}$ fat, $60 \mathrm{~g}$ protein \\
\hline HGI total & & $\begin{array}{l}7585 \mathrm{kj}(1806 \mathrm{kcal}), 287 \mathrm{~g} \mathrm{CHO}, 33.9 \mathrm{~g} \text { fat, } 83 \mathrm{~g} \text { protein } \\
(72 \% \mathrm{CHO}, 11 \% \text { fat, } 17 \% \text { protein }) \\
\mathrm{Gl}=70 \dagger\end{array}$ \\
\hline LGI total & & $\begin{array}{l}7589 \mathrm{kj}(1807 \mathrm{kcal}), 288 \mathrm{~g} \mathrm{CHO}, 34 \mathrm{~g} \text { fat, } 83 \mathrm{~g} \text { protein } \\
(72 \% \mathrm{CHO}, 11 \% \text { fat, } 17 \% \text { protein }) \\
\mathrm{Gl}=35 \dagger\end{array}$ \\
\hline
\end{tabular}

HGI, high glycaemic index; LGI, low glycaemic index; CHO, carbohydrate; Gl, glycaemic index.

${ }^{*}$ Corn Flakes, Kellogg's (UK) Ltd, Manchester, UK; Flora, ?: Lucozade Original drink, GlaxoSmithKline (UK)

†Calculated by the method described by Wolever \& Jenkins (1986) with Gl values taken from Foster-Powell et al. (2002).

method (Boehringer Mannheim, Mannheim Germany; $2 \times 20 \mu \mathrm{l}$ ) and haematocrit values were determined in triplicate on samples of whole blood by microcentrifugation (Hawksley Ltd, Lancing, Sussex, UK). Changes in plasma volume were estimated from changes in $\mathrm{Hb}$ concentrations and haematocrit values, as described by Dill \& Costill (1974). Blood lactate concentration was analysed by a photometric method using a spectrophotometer (UVmini1240; Shimadzu Corp., Kyoto, Japan). Plasma samples were obtained by centrifugation of the remaining whole blood for $10 \mathrm{~min}$ at $4000 \mathrm{rpm}$ and $4{ }^{\circ} \mathrm{C}$. The aliquoted plasma was then stored at $-85^{\circ} \mathrm{C}$ for later analysis of NEFA (ACS-ACOD method, Wako NEFA C; Wako, Neuss, Germany), glucose (GOD-PAP method; Randox Laboratories Ltd, Crumlin, Co. Antrim, Northern Ireland) and glycerol (Randox Laboratories Ltd) using an automatic photometric analyser (Cobas-Mira plus; Roche, Basel, Switzerland). The remaining whole blood sample was dispensed into a non-anticoagulant tube and left to clot for $45 \mathrm{~min}$. Serum samples were then obtained after centrifugation at $4000 \mathrm{rpm}$ for $10 \mathrm{~min}$ at $4{ }^{\circ} \mathrm{C}$. The aliquoted serum was stored at $-85^{\circ} \mathrm{C}$ and later analysed for insulin (Coat-A-Count Insulin; ICN Ltd, Eschwege, Germany) by RIA using a $\gamma$ counter (Cobra 5000; Packard Ltd, Boston, MA, USA). Pre-trial urine samples were measured for osmolality using a cryoscopic osmometer (Gonometer 030; Gonotec, Berlin, Germany) and adequate hydration was assumed for osmolality values below 900 mosmol/kg (Shirreffs \& Maughan, 1998).

\section{Expired gas sample collection and analysis}

Samples of expired gas were collected using the Douglas bag method. During rest, samples were collected pre-meal and at $15,30,60,90,120$ and $180 \mathrm{~min}$ throughout the postprandial periods. Expired gas samples were also collected at $15 \mathrm{~min}$ intervals throughout the run. Running samples were collected for $1 \mathrm{~min}$ and resting samples for $5 \mathrm{~min}$. Substrate oxidation rates and energy expenditure were calculated from $\mathrm{O}_{2}$ consumption and $\mathrm{CO}_{2}$ production values using stoichiometric equations (Frayn, 1983). During each sample, ratings of perceived exertion (Borg, 1973), perceived gut fullness and hunger were recorded on a scale from 6 to 20. Total $\mathrm{CHO}$ and fat oxidation was estimated from the area under the rate of oxidation $v$. time curve for each subject.

\section{Statistical analysis}

ANOVA for repeated measures on two factors (experimental treatment and time) was used to analyse differences in the physiological and metabolic responses in both trials. If a significant interaction was obtained, a Holm-Bonferroni stepwise post hoc test was applied to determine the location of the variance. Differences were considered significant at $P<0 \cdot 05$. All results are presented as means with their standard errors.

\section{Results}

\section{Plasma glucose and serum insulin}

Following ingestion of the HGI and LGI breakfasts, plasma glucose concentrations increased and peaked at $15 \mathrm{~min}$ during the postprandial period (6.89 (SEM 0.31) and 5.10 (SEM 0.40) $\mathrm{mmol} / 1$, respectively, $P<0.01$; Fig. 1 ). Thereafter, plasma glucose concentrations decreased below fasting values by $30 \mathrm{~min}$ in the LGI trial and $60 \mathrm{~min}$ in the HGI trial and continued to decrease throughout the postprandial period. Following the ingestion of the HGI and LGI lunch, plasma glucose concentrations again peaked at $15 \mathrm{~min}$ during the postprandial period (6.96 (SEM 0.39 ) and 5.42 (SEM 0.28$) \mathrm{mmol} / \mathrm{l}$, respectively, $P<0.05$ ). Following this peak, a sharp decline in plasma glucose concentrations was observed in both trials; however, during the $2 \mathrm{~h}$ before the start of exercise, plasma glucose concentrations were equally maintained at approximately $5 \mathrm{mmol} / \mathrm{l}$. During the first $30 \mathrm{~min}$ of exercise, there were no differences in plasma glucose concentrations between trials. At $45 \mathrm{~min}$, plasma glucose concentrations were higher in the LGI trial than in the HGI trial (5.47 (SEM 0.13) and 4.91 (SEM 0.18 ) $\mathrm{mmol} / \mathrm{l}$, respectively, $P<0 \cdot 01$ ). At the end of the $60 \mathrm{~min}$ run, plasma glucose concentrations were still higher in the LGI trial compared with the HGI trial (5.69 (SEM 0.09) and 4.92 (SEM 0.16) mmol/l, respectively, $P<0.001$ ).

In both trials, serum insulin concentrations peaked at $15 \mathrm{~min}$ during the postprandial period following breakfast (HGI: 926.7 (SEM 141.1) and LGI: 644.0 (SEM 73.2) pmol/l, $P<0.05$; Fig. 2). 


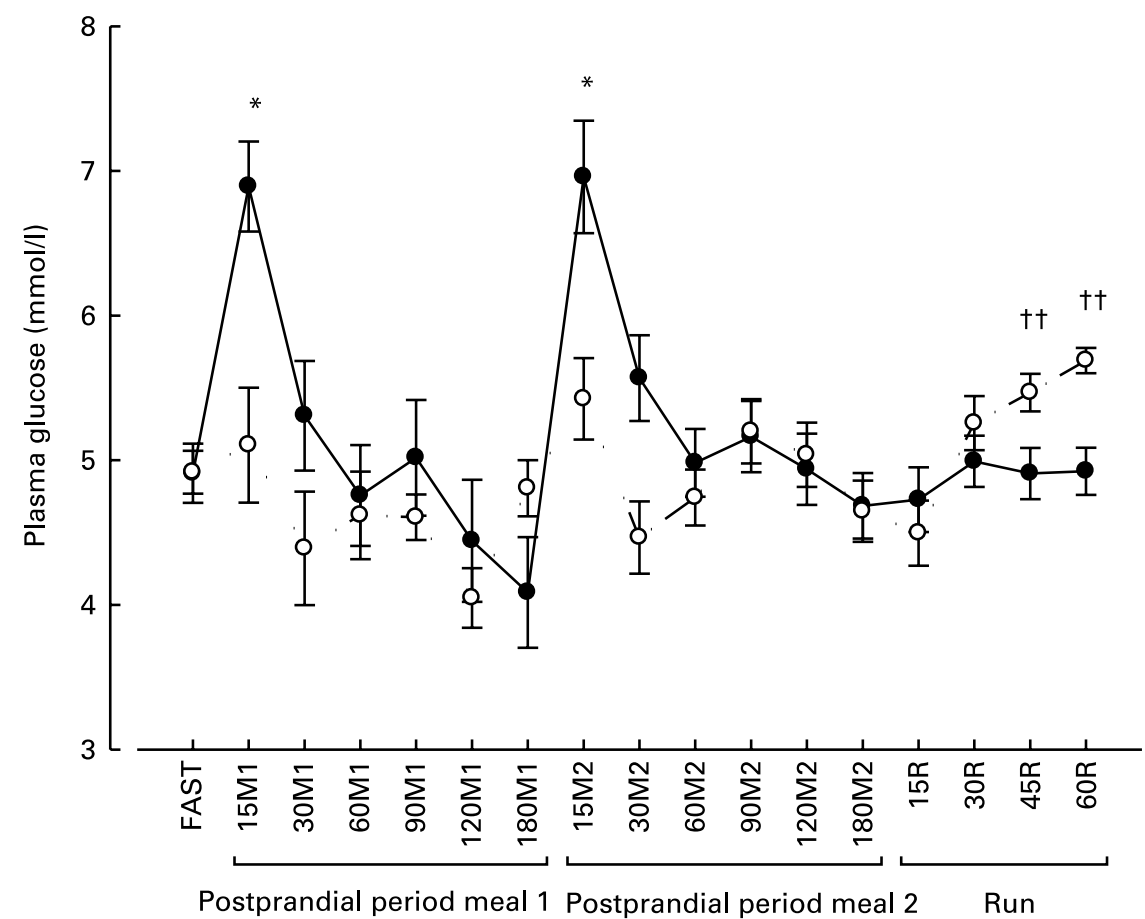

Fig. 1. Plasma glucose concentrations (mmol/l) in the high glycaemic index (HGl; - - ) and low glycaemic index (LGI; --O--) carbohydrate trials. Fasting value (FAST), values obtained during the postprandial period 15, 30, 60, 90, 120 and 180 min after meal 1 (breakfast; 15M1, 30M1, 60M1, 90M1, 120 M1 and $180 \mathrm{M} 1$, respectively) and meal 2 (lunch; 15M2, 30M2, 60M2, 90M2, 120M2 and 180M2, respectively) and values obtained at 15 , 3045 and 60 min during subsequent exercise (run; 15R, 30R, 45R and 60R, respectively). Values are means with their standard errors shown by vertical bars. Mean values were significantly higher in HGI trial $v$. LGI trial: ${ }^{*} P<0.05$; mean values were significantly higher in LGI trial $v$. $\mathrm{HGI}$ trial: $\dagger \dagger P<0 \cdot 01$.

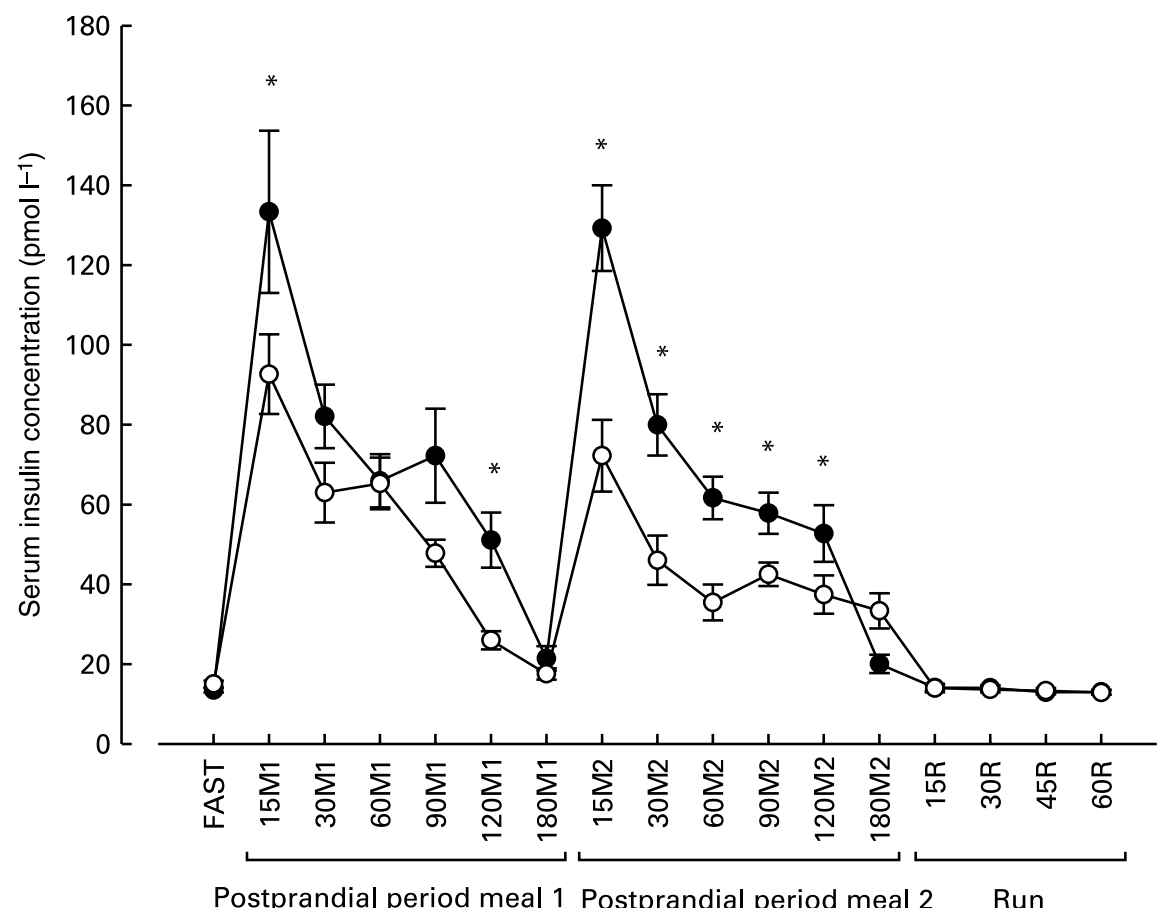

Fig. 2. Serum insulin concentrations (pmol. $\mathrm{I}^{-1}$,) in the high glycaemic index (HGl; - - ) and low glycaemic index (LGI; --O--) carbohydrate trials. Fasting value (FAST), values obtained during the postprandial period 15, 30, 60, 90, 120 and 180 min after meal 1 (breakfast; 15M1, 30M1, 60M1, 90M1, 120M1 and $180 \mathrm{M} 1$, respectively) and meal 2 (lunch; 15M2, 30M2, 60M2, 90M2, $120 \mathrm{M} 2$ and 180M2, respectively) and values obtained at 15 , 3045 and 60 min during subsequent exercise (run; 15R, 30R, 45R and 60R, respectively). Values are means with their standard errors shown by vertical bars. Mean values were significantly higher in HGI trial $v$. LGI trial: ${ }^{*} P<0.05$. 
Serum insulin concentrations then declined throughout the postprandial period but were higher in the HGI trial than in the LGI trial at $120 \mathrm{~min}(P<0 \cdot 05)$. Following the ingestion of lunch, serum insulin concentrations again peaked at $15 \mathrm{~min}$ during the postprandial period. Once again, the peak was greater in the HGI trial than in the LGI trial (873.5 (SEM 75.4) and 502.0 (SEM 65.9) pmol/l, respectively, $P>0.05$ ). Throughout the rest of the postprandial period following lunch, serum insulin concentrations decreased but remained higher in the HGI trial than in the LGI trial $(P<0 \cdot 05)$. No differences were observed between trials once exercise commenced.

\section{Plasma NEFA and glycerol}

Plasma NEFA concentrations were reduced following the consumption of both the HGI and LGI breakfasts and remained reduced throughout both postprandial periods (Fig. 3). Throughout the exercise period, plasma NEFA increased gradually in both trials; however, no differences between the trials were seen. Plasma glycerol concentrations showed a similar response to that of plasma NEFA. Once again, there were no significant differences between the trials (Fig. 4).

\section{Blood lactate}

Following ingestion of breakfast, blood lactate concentrations were significantly higher in the LGI trial compared with the HGI trial for the first $90 \mathrm{~min}$ of the postprandial period $(P<0.01$; Fig. 5). No differences were observed between trials following lunch or throughout the $60 \mathrm{~min}$ run.

\section{Estimated carbohydrate and fat oxidation rates}

There were no differences in the estimated total amount of $\mathrm{CHO}$ or fat oxidised throughout the postprandial period following breakfast. In contrast, following lunch, the calculated total amount of $\mathrm{CHO}$ oxidised was higher in the HGI trial than in the LGI trial (HGI: 71.7 (SEM 3.4) and LGI: 58.9 (SEM 3.3) g/3 h, $P<0.005$; Fig. 6) and the estimated total amount of fat oxidised was higher in the LGI than in the HGI trial (LGI: 12.5 (SEM 1.1) and HGI: 9.0 (SEM 1.1) g/3 h, $P<0.01$; Fig. 7).

During the exercise period, there were no differences in the total amount of $\mathrm{CHO}$ oxidised (HGI: 215.7 (SEM 8.0) and LGI: $214.4($ SEM 12.6) $\mathrm{g} / \mathrm{h}$ ) or total amount of fat oxidised (HGI: $11 \cdot 5$ (SEM 2.3) and LGI: $10 \cdot 9$ (SEM 2.5) g/h).

\section{Heart rate and rate of perceived exertion}

There were no significant differences between heart rate and rate of perceived exertion between the trials.

\section{Hydration status and plasma volume}

There were no significant differences in urine osmolality at the start of each trial (592 (SEM 118) and 631 (SEM 113) mosmol/ $\mathrm{kg}$ in the HGI and LGI trials, respectively). Using a cut-off point of $900 \mathrm{mosmol} / \mathrm{kg}$, none of the values suggested that any of the participants began the trials in a dehydrated state. There were no significant differences in plasma volume between trials.

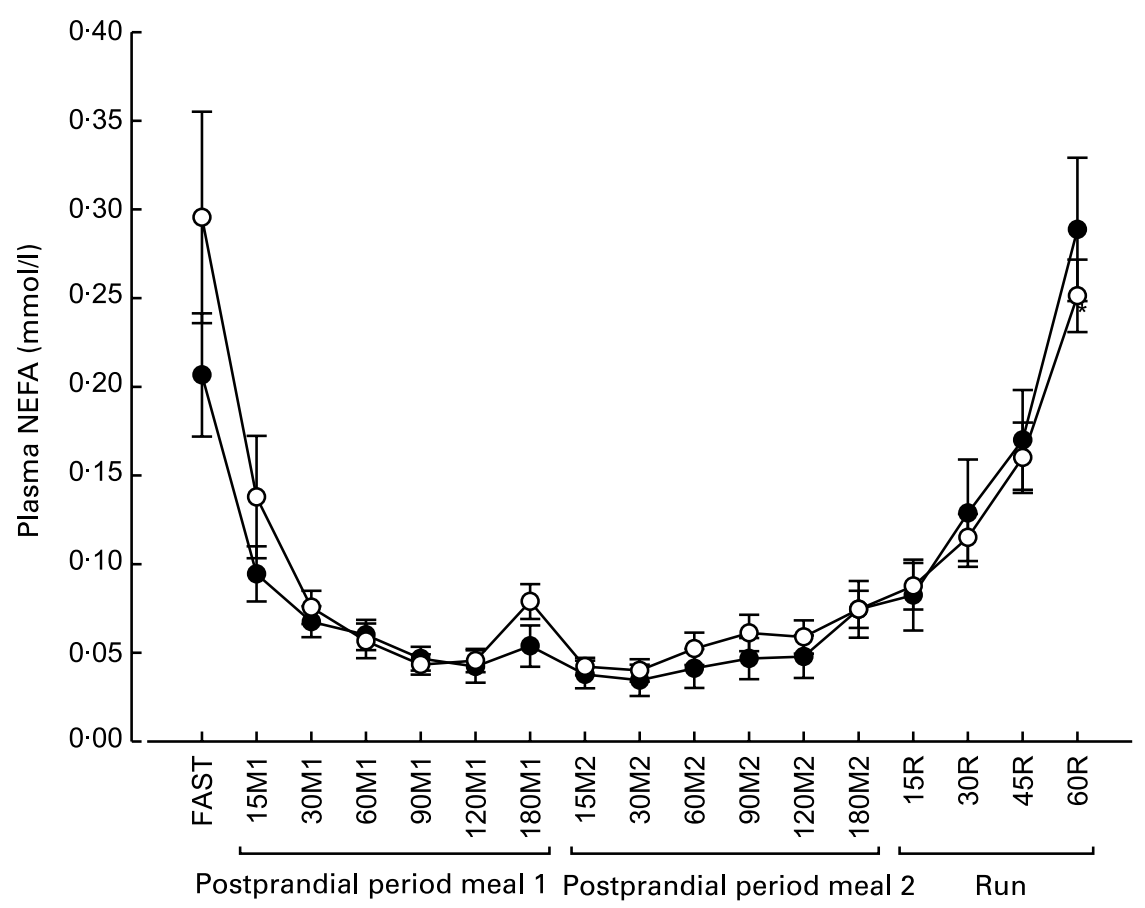

Fig. 3. Plasma NEFA concentrations (mmol/l) in the high glycaemic index (- - - ) and low glycaemic index (--O--) carbohydrate trials. Fasting value (FAST), values obtained during the postprandial period 15, 30,60, 90, 120 and 180 min after meal 1 (breakfast; 15M1, 30M1, 60M1, 90M1, 120M1 and 180M1, respectively) and meal 2 (lunch; 15M2, 30M2, 60M2, 90M2, 120M2 and 180M2, respectively) and values obtained at 15,3045 and 60 min during subsequent exercise (run; 15R, 30R, 45R and 60R, respectively). Values are means with their standard errors shown by vertical bars. 


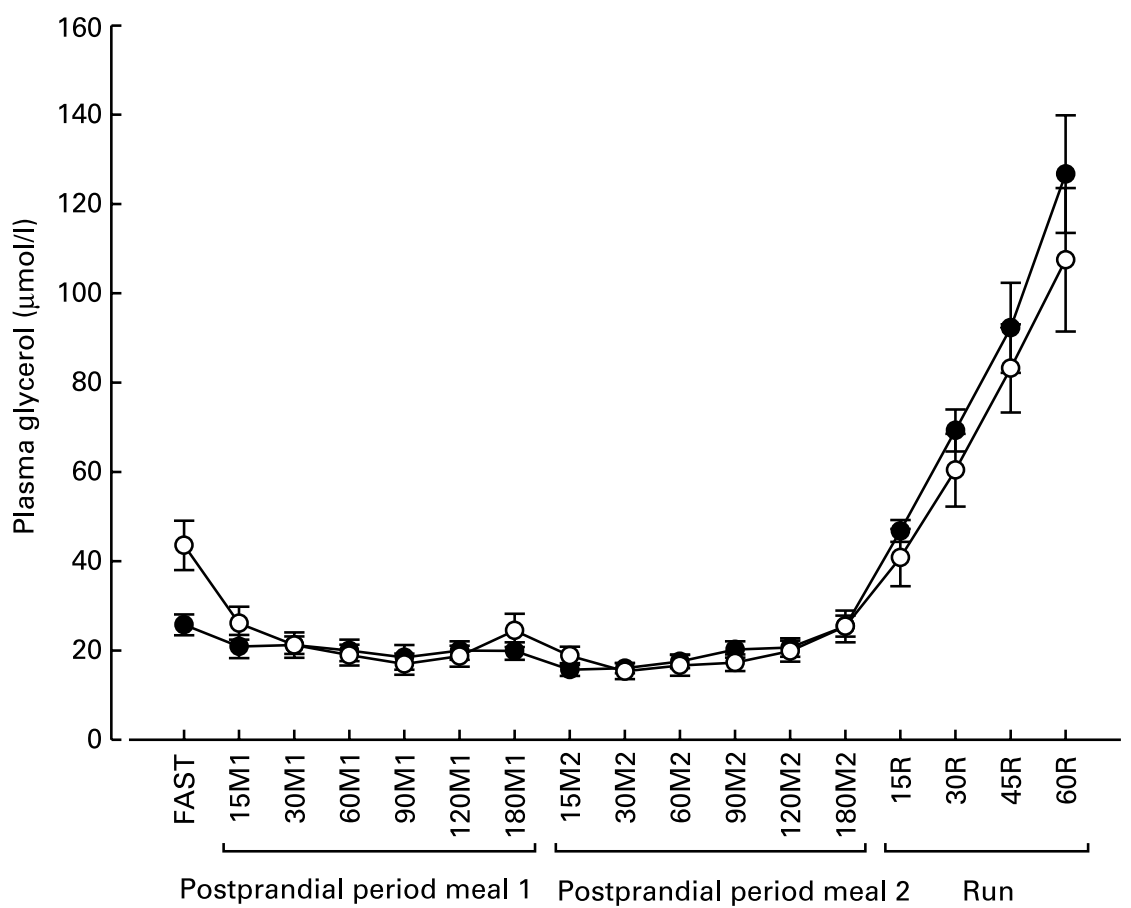

Fig. 4. Plasma glycerol concentrations ( $\mu \mathrm{mol} / \mathrm{l})$ in the high glycaemic index (--) and low glycaemic index (-- ---$)$ carbohydrate trials. Fasting value (FAST), values obtained during the postprandial period 15, 30, 60, 90, 120 and 180 min after meal 1 (breakfast; 15M1, 30M1, 60M1, 90M1, 120M1 and 180M1, respectively) and meal 2 (lunch; 15M2, 30M2, 60M2, 90M2, 120M2 and 180M2, respectively) and values obtained at 15, 3045 and 60 min during subsequent exercise (run; 15R, 30R, 45R and 60R, respectively). Values are means with their standard errors shown by vertical bars.

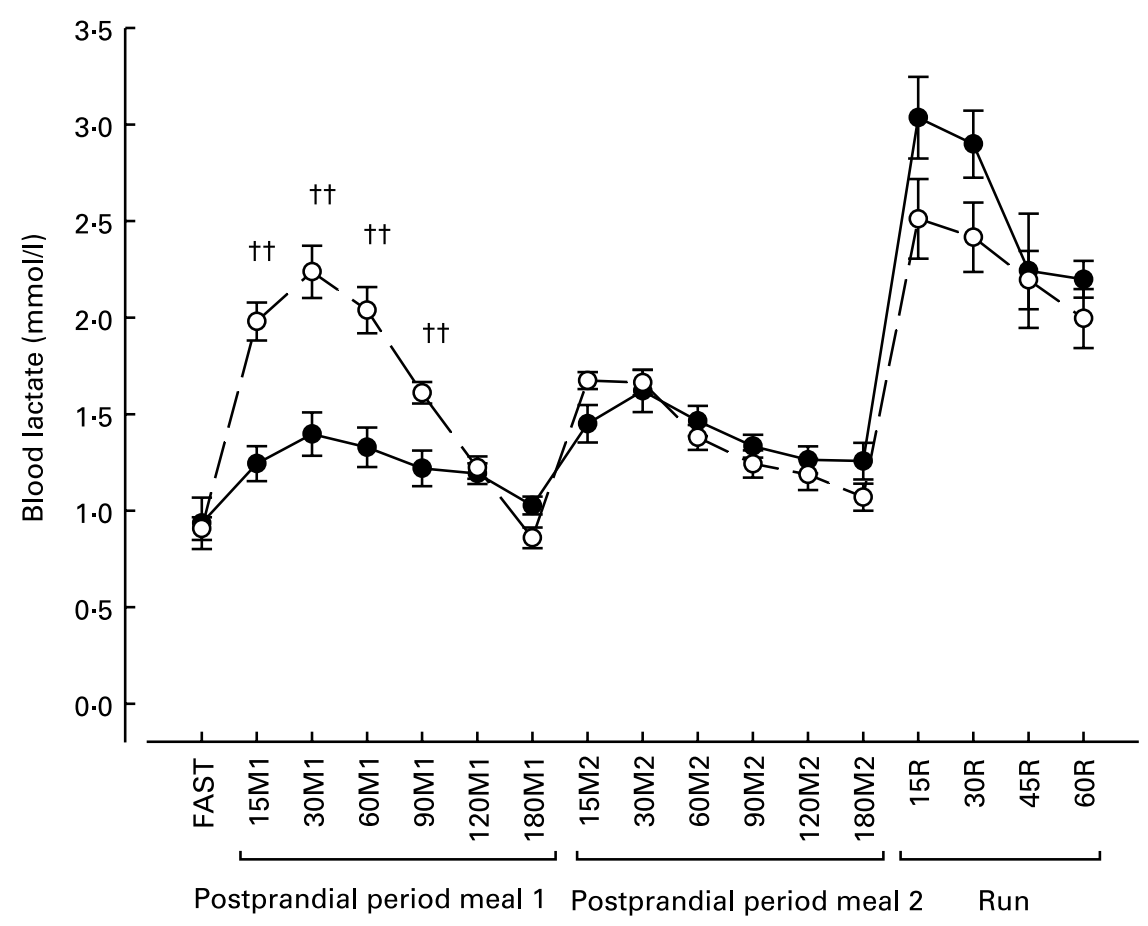

Fig. 5. Blood lactate concentrations (mmol/l) in the high glycaemic index (HGl; - - -) and low glycaemic index (LGl; --O--) carbohydrate trials. Fasting value (FAST), values obtained during the postprandial period 15, 30, 60, 90, 120 and 180 min after meal 1 (breakfast; 15M1, 30M1, 60M1, 90M1, 120M1 and 180M1, respectively) and meal 2 (lunch; 15M2, 30M2, 60M2, 90M2, 120M2 and 180M2, respectively) and values obtained at 15, 3045 and 60 min during subsequent exercise (run; 15R, 30R, 45R and 60R, respectively). Values are means with their standard errors shown by vertical bars. Mean values were significantly higher in LGI trial $v$. HGI trial: $\dagger+P<0.01$. 


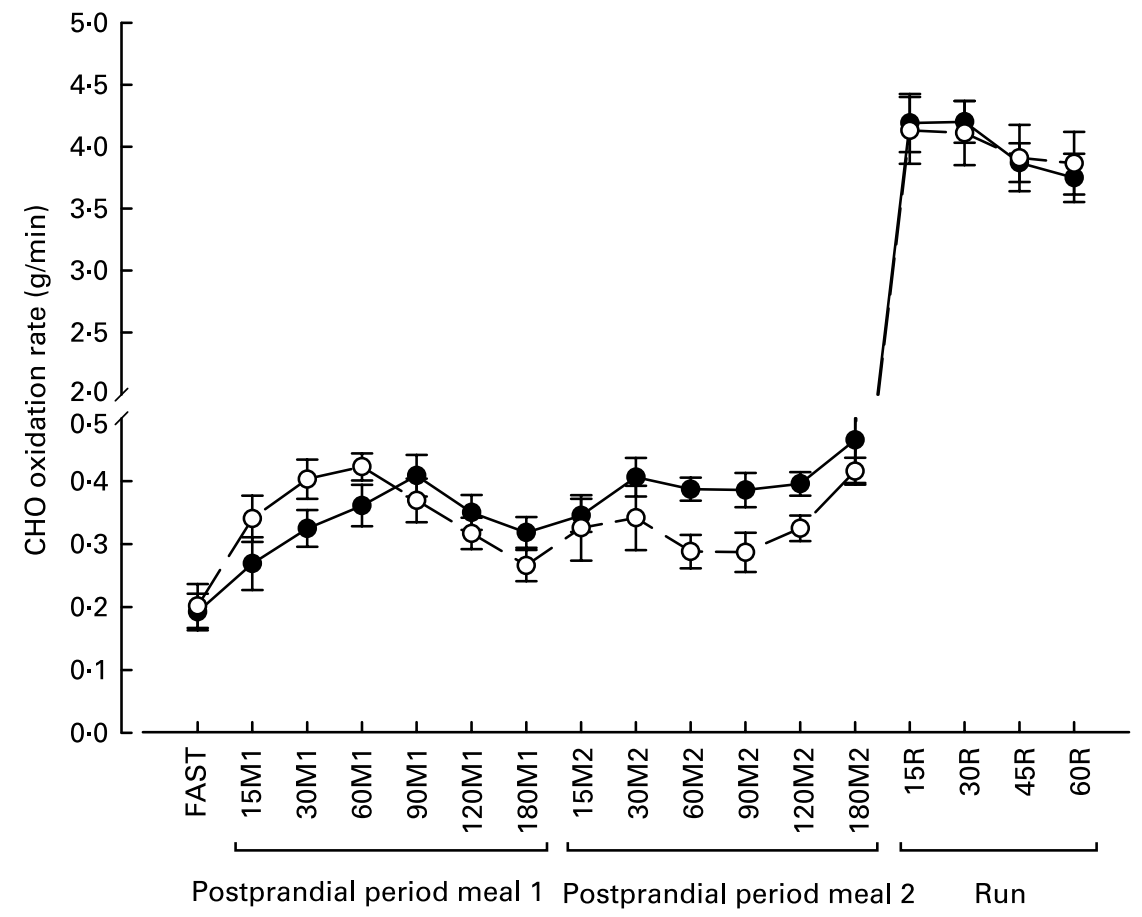

Fig. 6. Estimated rate of carbohydrate $(\mathrm{CHO})$ oxidation $(\mathrm{g} / \mathrm{min})$ in the high glycaemic index $(-\bullet-)$ and low glycaemic index $(--\mathrm{O}--)$ CHO trials. Fasting value (FAST), values obtained during the postprandial period 15,30,60, 90, 120 and 180 min after meal 1 (breakfast; 15M1, 30M1, 60M1, 90M1, 120M1 and 180M1, respectively) and meal 2 (lunch; 15M2, 30M2, 60M2, 90M2, 120M2 and 180M2, respectively) and values obtained at 15, 3045 and 60 min during subsequent exercise (run; 15R, 30R, 45R and 60R, respectively). Values are means with their standard errors shown by vertical bars.

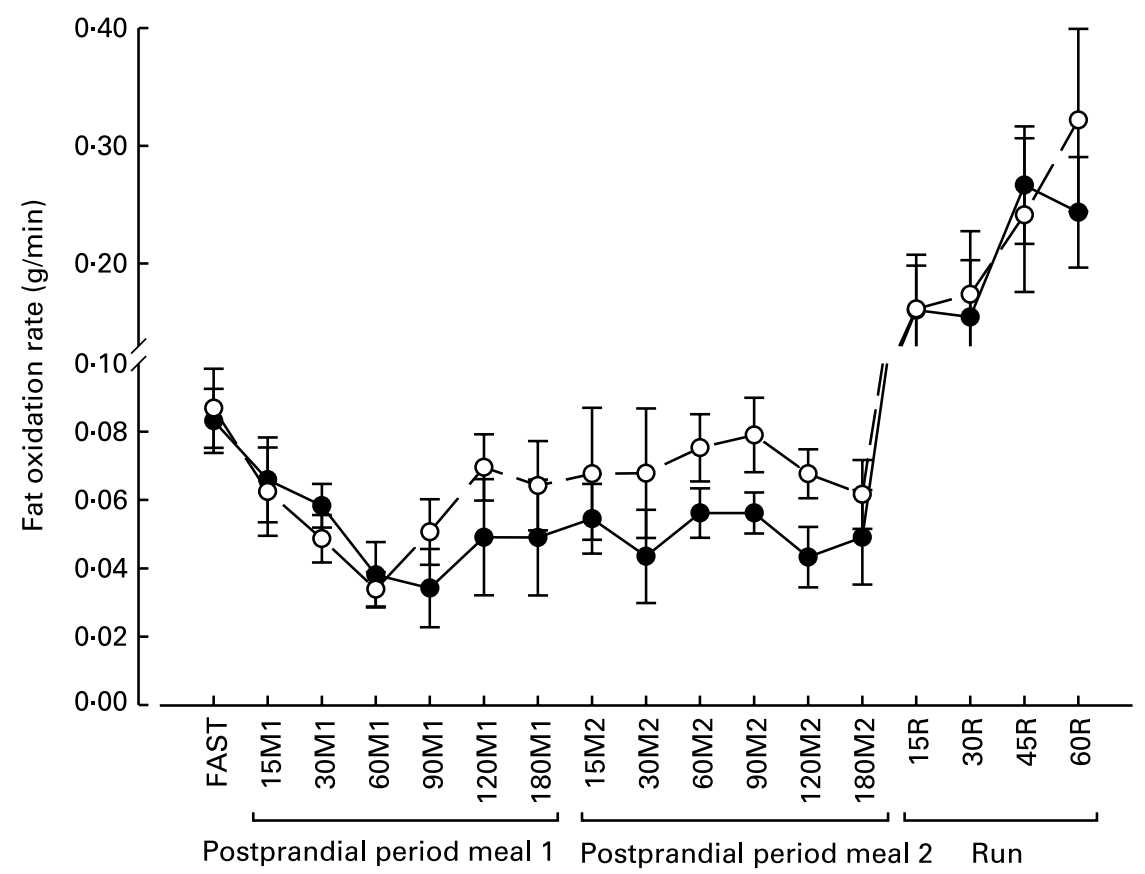

Fig. 7. Estimated rate of fat oxidation ( $\mathrm{g} / \mathrm{min})$ in the high glycaemic index (-- - ) and low glycaemic index (--O--) carbohydrate trials. Fasting value (FAST), values obtained during the postprandial period 15, 30, 60, 90, 120 and 180 min after meal 1 (breakfast; 15M1, 30M1, 60M1, 90M1, 120M1 and 180M1, respectively) and meal 2 (lunch; 15M2, 30M2, 60M2, 90M2, 120M2 and 180M2, respectively) and values obtained at 15, 3045 and 60 min during subsequent exercise (run; 15R, 30R, 45R and 60R, respectively). Values are means with their standard errors shown by vertical bars. 


\section{Gut fullness and hunger scales}

Ratings of perceived hunger were significantly lower during the postprandial period following the LGI lunch compared with the HGI lunch $(P<0 \cdot 05)$. There were no significant differences in gut fullness between trials (Table 2).

\section{Discussion}

The main aim of the present study was to investigate the metabolic responses to HGI and LGI mixed meals. The metabolic responses to single foods with different GI are now well understood; however, data are deficient on the responses to mixed meals with nutrient compositions that are clearly within prevailing norms (Ludwig \& Jenkins, 2004). During the postprandial periods following both of the meals, plasma glucose concentrations and serum insulin concentrations were significantly higher in the HGI trial than in the LGI trial. The validity of the GI values of mixed meals has been questioned in several studies (Coulston et al. 1984; Hollenbeck et al. 1988). The results from the present study show that significant differences in hyperglycaemia and hyperinsulinaemia can repeatedly be achieved by changing the GI of the $\mathrm{CHO}$ in a mixed meal. This therefore offers support for calculation of the GI values for mixed meals suggested by Wolever \& Jenkins (1986).

The postprandial metabolic responses to CHO-dense HGI foods like those described earlier have been used to provide a possible explanation as to why low-fat diets have not lived up to their potential to inhibit weight gain when consumed ad libitum (Brand-Miller et al. 2002). Postprandial hyperglycaemia and hyperinsulinaemia promote postprandial $\mathrm{CHO}$ oxidation at the expense of fat oxidation, thus altering fuel partitioning that may be conducive to body fat gain. LGI diets have therefore been promoted as an effective weight control method as they minimise postprandial insulin secretion, therefore promoting fat oxidation.

In the present study, the amount of fat oxidised during the postprandial period following lunch was significantly higher in the LGI trial $v$. the HGI trial. This is in contrast to previous studies investigating pre-exercise feeding and GI that reported no differences in substrate oxidation at rest during the postprandial period following a single LGI food or meal (Wee et al. 1999; Wu et al. 2003). It is important to highlight, however, that previous studies in this area have only investigated the metabolic responses to a single meal or one portion of a single food and the differences in the present study were apparent only after the second meal.
It is not possible to speculate on the chronic effects of a LGI diet from these data; however, the results of the present study provide evidence that changes in fuel partitioning and substrate oxidation can occur even over a single day when consuming LGI $\mathrm{CHO}$ instead of HGI CHO.

LGI foods are also reported to be beneficial for weight loss because their consumption has been reported to result in a prolonged feeling of satiety and therefore reduced hunger and food intake (Ludwig et al. 1999; Warren et al. 2003). In the present study, ratings of gut fullness and hunger were recorded at regular intervals following breakfast and lunch in both trials. Hunger ratings were significantly lower in the LGI trial than in the HGI trial despite the meals being matched for energy and nutrient content.

Interestingly, blood lactate concentrations were significantly elevated following ingestion of the LGI breakfast whereas the increase was minimal following the HGI breakfast. Several studies have reported that $\mathrm{CHO}$ that have high fructose concentrations result in higher blood lactate concentrations (Koivisto et al. 1981; Moore et al. 2000). Once fructose enters the cell, it is rapidly converted to fructose-1-phosphate. The high concentrations of fructose-1-phosphate inhibit the degradation of glycogen and facilitate the production of lactate (Henry et al. 1991). About twothirds of fructose is converted to glucose and the rest of the metabolised fructose is released from the liver as lactate (Henry et al. 1991). In the present study, the LGI breakfast contained more fructose $(25 \mathrm{~g} / 70 \mathrm{~kg}$ man) than the HGI breakfast $(11 \mathrm{~g} / 70 \mathrm{~kg}$ man). This may therefore explain the higher blood lactate concentrations in the LGI trial during the postprandial period. Similar blood lactate results were also reported by Wu et al. (2003), who used similar breakfasts to those in the present study.

The second aim of the present study was to investigate the effects of the GI of breakfast and lunch on substrate utilisation during a subsequent $60 \mathrm{~min}$ run at $70 \% \dot{\mathrm{VO}}_{2 \max }$. A previous study from our laboratory reported that the calculated rate of fat oxidation was significantly higher during $60 \mathrm{~min}$ exercise commencing $3 \mathrm{~h}$ after consuming a LGI meal than the fat oxidation following a HGI meal (Wu et al. 2003). In the present study, two LGI meals were provided in the $6 \mathrm{~h}$ before the exercise bout; however, the calculated rate of fat oxidation during exercise was not different compared with when two HGI meals were provided. It is important to note that the exercise intensity in the present study $\left(70 \% \dot{\mathrm{V}}_{2 \max }\right)$ was higher than in Wu et al.'s study $\left(65 \% \dot{\mathrm{V}}_{2 \max }\right)$. The exercise intensity that elicits the maximal rate of fat oxidation has recently been reported to be between approximately $50 \%$ and $64 \% \quad \dot{V}_{2 \max }$ (Achten et al. 2002).

Table 2. Ratings of gut fullness and hunger during the high glycaemic index ( $\mathrm{HGl}$ ) and low glycaemic index (LGI) carbohydrate trials

(Values are means with their standard errors)

\begin{tabular}{|c|c|c|c|c|c|c|c|c|c|}
\hline \multirow[b]{3}{*}{ Variable } & \multirow[b]{3}{*}{ Trial } & \multirow{2}{*}{\multicolumn{2}{|c|}{ Resting }} & \multicolumn{4}{|c|}{ Postprandial period } & & \\
\hline & & & & \multicolumn{2}{|c|}{ Breakfast } & \multicolumn{2}{|c|}{ Lunch } & \multicolumn{2}{|c|}{$\begin{array}{c}\text { Exercise } \\
\text { period }\end{array}$} \\
\hline & & Mean & SEM & Mean & SEM & Mean & SEM & Mean & SEM \\
\hline \multirow[t]{2}{*}{ Gut fullness } & $\mathrm{HGI}$ & 8 & 0 & 10 & 0 & 11 & 1 & 10 & 1 \\
\hline & LGI & 8 & 1 & 10 & 0 & 11 & 0 & 11 & 1 \\
\hline \multirow[t]{2}{*}{ Hunger } & $\mathrm{HGI}$ & 13 & 1 & 11 & 1 & 11 & 1 & 8 & 1 \\
\hline & LGI & 14 & 1 & 10 & 1 & $9^{*}$ & 1 & 8 & 0 \\
\hline
\end{tabular}

Mean values were significantly different from those in the $\mathrm{HGI}$ trial: ${ }^{\star} P<0.05$. 
Therefore, it is possible that the exercise intensity in the present study was too high to highlight any differences in substrate oxidation.

At $45 \mathrm{~min}$ into the run and on completion of the $60 \mathrm{~min}$, plasma glucose concentrations were significantly higher in the LGI trial compared with the HGI trial. Other studies investigating the effect of the GI of pre-exercise feedings have reported higher plasma glucose concentrations towards the end of an exercise session following a LGI meal (Thomas et al. 1991, 1994; DeMarco et al. 1999). LGI CHO theoretically release glucose from the gut at a slower rate and therefore for an extended period (DeMarco et al. 1999). Hence, this would allow maintenance of blood glucose for a longer period of time compared with HGI CHO.

The clinical relevance of the GI has been vigorously debated in recent years (Ludwig, 2002) and some believe that the concept may be too complicated to be practical. The results of the present study show that the GI concept can be successfully applied to mixed meals that would be consumed in a real-life setting. Although no differences in substrate oxidation were seen during exercise at the end of the day, the results of the present study show that the GI of the meals consumed at breakfast and lunch can alter substrate oxidation during the postprandial periods whilst at rest.

\section{References}

Achten J, Gleeson M \& Jeukendrup AE (2002) Determination of the exercise intensity that elicits maximal fat oxidation. Med Sci Sports Exerc 34, 92-97.

Borg GA (1973) Perceived exertion: a note on 'history' and methods. Med Sci Sports 5, 90-93.

Brand-Miller JC, Holt SH, Pawlak DB \& McMillan J (2002) Glycemic index and obesity. Am J Clin Nutr 76, 281S-285S.

Collier G, McLean A \& O'Dea K (1984) Effect of co-ingestion of fat on the metabolic responses to slowly and rapidly absorbed carbohydrates. Diabetologia 26, 50-54.

Coulston AM, Hollenbeck CB, Liu GC, Williams RA, Starich GH, Mazzaferri EL \& Reaven GM (1984) Effect of source of dietary carbohydrate on plasma glucose, insulin, and gastric inhibitory polypeptide responses to test meals in subjects with noninsulin-dependent diabetes mellitus. Am J Clin Nutr 40, 965-970.

Coulston AM, Hollenbeck CB, Swislocki AL \& Reaven GM (1987) Effect of source of dietary carbohydrate on plasma glucose and insulin responses to mixed meals in subjects with NIDDM. Diabetes Care 10, 395-400.

Coyle EF, Jeukendrup AE, Wagenmakers AJ \& Saris WH (1997) Fatty acid oxidation is directly regulated by carbohydrate metabolism during exercise. Am J Physiol 273, E268-E275.

DeMarco HM, Sucher KP, Cisar CJ \& Butterfield GE (1999) Pre-exercise carbohydrate meals: application of glycemic index. Med Sci Sports Exerc 31, 164-170.

Dill DB \& Costill DL (1974) Calculation of percentage changes in volumes of blood, plasma, and red cells in dehydration. J Appl Physiol 37, 247-248.

Febbraio MA \& Stewart KL (1996) CHO feeding before prolonged exercise: effect of glycemic index on muscle glycogenolysis and exercise performance. J Appl Physiol 81, 1115-1120.

Foster-Powell K, Holt SH \& Brand-Miller JC (2002) International table of glycemic index and glycemic load values: 2002. Am J Clin Nutr 76, $5-56$
Frayn KN (1983) Calculation of substrate oxidation rates in vivo from gaseous exchange. J Appl Physiol 55, 628-634.

Henry RR, Crapo PA \& Thorburn AW (1991) Current issues in fructose metabolism. Annu Rev Nutr 11, 21-39.

Hollenbeck CB, Coulston AM \& Reaven GM (1988) Comparison of plasma glucose and insulin responses to mixed meals of high-, intermediate-, and low-glycemic potential. Diabetes Care 11, 323-329.

Horowitz JF, Mora-Rodriguez R, Byerley LO \& Coyle EF (1997) Lipolytic suppression following carbohydrate ingestion limits fat oxidation during exercise. Am J Physiol 273, E768-E775.

Koivisto VA, Karonen SL \& Nikkila EA (1981) Carbohydrate ingestion before exercise: comparison of glucose, fructose, and sweet placebo. J Appl Physiol 51, 783-787.

Ludwig DS (2002) The glycemic index: physiological mechanisms relating to obesity, diabetes, and cardiovascular disease. JAMA $\mathbf{2 8 7}$, 2414-2423.

Ludwig DS \& Jenkins DJ (2004) Carbohydrates and the postprandial state: have our cake and eat it too? Am J Clin Nutr 80, 797-798.

Ludwig DS, Majzoub JA, Al-Zahrani A, Dallal GE, Blanco I \& Roberts SB (1999) High glycemic index foods, overeating, and obesity. Pediatrics 103, E26.

Moore MC, Cherrington AD, Mann SL \& Davis SN (2000) Acute fructose administration decreases the glycemic response to an oral glucose tolerance test in normal adults. J Clin Endocrinol Metab 85, 4515-4519.

Nilsson LH \& Hultman E (1973) Liver glycogen in man - the effect of total starvation or a carbohydrate-poor diet followed by carbohydrate refeeding. Scand J Clin Lab Invest 32, 325-330.

Pi-Sunyer FX (2002) Glycemic index and disease. Am J Clin Nutr 76, 290S-298S.

Shirreffs SM \& Maughan RJ (1998) Urine osmolality and conductivity as indices of hydration status in athletes in the heat. Med Sci Sports Exerc 30, 1598-1602.

Sparks MJ, Selig SS \& Febbraio MA (1998) Pre-exercise carbohydrate ingestion: effect of the glycemic index on endurance exercise performance. Med Sci Sports Exerc 30, 844-849.

Thomas DE, Brotherhood JR \& Brand JC (1991) Carbohydrate feeding before exercise: effect of glycemic index. Int J Sports Med 12, $180-186$.

Thomas DE, Brotherhood JR \& Miller JB (1994) Plasma glucose levels after prolonged strenuous exercise correlate inversely with glycemic response to food consumed before exercise. Int J Sport Nutr 4, $361-373$.

Warren JM, Henry CJ \& Simonite V (2003) Low glycemic index breakfasts and reduced food intake in preadolescent children. Pediatrics 112, e414.

Wee SL, Williams C, Gray S \& Horabin J (1999) Influence of high and low glycemic index meals on endurance running capacity. Med Sci Sports Exerc 31, 393-399.

Williams C, Nute MG, Broadbank L \& Vinall S (1990) Influence of fluid intake on endurance running performance. A comparison between water, glucose and fructose solutions. Eur J Appl Physiol Occup Physiol 60, 112-119.

Wolever TM \& Jenkins DJ (1986) The use of glycemic index in predicting the blood glucose response to mixed meals. Am J Clin Nutr 43, $167-172$.

Wu CL, Nicholas C, Williams C, Took A \& Hardy L (2003) The influence of high-carbohydrate meals with different glycaemic indices on substrate utilisation during subsequent exercise. Br J Nutr 90, 1049-1056. 